\title{
Nanotechnologies: A Key Role in Virus Fight
}

\author{
Christophe Drouet* \\ CIRIMAT, Université de Toulouse, CNRS, France
}

*Corresponding author: Christophe Drouet, CIRIMAT Ensiacet-4 allée Emile Monso, 31030 Toulouse cedex 4, France

\begin{tabular}{|c|c|}
\hline ARTICLE INFO & ABSTRACT \\
\hline Received: 慧 April 24, 2020 & \multirow{4}{*}{$\begin{array}{l}\text { Zika, Ebola, Covid-19... Viruses from their nanoworld are at the origin of major } \\
\text { health challenges and may cause pandemic threats. In the crusade for virus fight, } \\
\text { being "small" may be an asset, for being active at the right scale. Nanosystems have } \\
\text { recurrently been used to enhance the immune response of the body, by themselves } \\
\text { or in combination with active agents (e.g. antigens) as well as for virus detection and } \\
\text { isolation. This article is not an exhaustive review, but it envisions giving a general } \\
\text { overview of the rationale behind the use of nanotechnology in virus fight, as illustrated } \\
\text { by several significant examples including recentfindings. Nanosystems, andin particular } \\
\text { inorganic nanoparticles, offer a large variety of declinations that may be tailored in } \\
\text { terms of physical and chemical characteristics to address the needs of virology. Among } \\
\text { them, noble metals, metal oxides, mesoporous silica and calcium phosphates showed } \\
\text { special promise. In particular, the bio-inspired character and modularity of calcium } \\
\text { phosphates is appealing and allows envisioning further original developments in the } \\
\text { fight against infections. }\end{array}$} \\
\hline Published: 蔧 May 04, 2020 & \\
\hline $\begin{array}{l}\text { Citation: Christophe Drouet. Nanotech- } \\
\text { nologies: A Key Role in Virus Fight . Bi- } \\
\text { omed J Sci \& Tech Res 27(2)-2020. BJSTR. } \\
\text { MS.ID.004500. }\end{array}$ & \\
\hline $\begin{array}{l}\text { Keywords: Virus; Pandemic; Nanotechnol- } \\
\text { ogy; Vaccine; Adjuvant; Calcium Phosphate; } \\
\text { Apatite; Nanocarrier }\end{array}$ & \\
\hline
\end{tabular}

\section{Introduction}

\section{It Is A Small World After All!}

All the matter that surrounds us is based on associations of elementary particles forming atoms, themselves organized in molecules and crystals often of submillimetric dimensions. Microbial life in the form of bacteria, fungi and other microorganisms is ubiquitous on Earth and plays a fundamental role, as in plant nutrition in soils [1]. The human body itself counts at least as many bacterial cells as human cells [2]. And all of these cellular entities measuring few microns at most -- ensure the biological machinery of the whole body. The "small world" is not far from ruling our lives... and infectious pathogens also play the game. Besides the vast majority of harmless bacteria necessary to the life of most superior animals including humans, a significantly more limited number of bacteria are, in contrast, pathogenic and may cause infectious diseases [3]. Among illustrious bacteria-bound infections, on can cite for example tuberculosis, cholera, or else bone infections involving Staphylococcus aureus. But other smaller pathogens also come into play: viruses. They are an elaborate form of parasites, requiring penetration into live cells for viral replication. Viruses consist in a nucleic acid component expressing the virus genome (in the form of single- or double-stranded RNA or DNA) protected by a proteic envelope, the capsid. In some cases, the capsid itself is also surrounded by a phospholipid-based membrane [4]. Among critically lethal viruses are Ebola, Rabies, HIV and others. Viruses such as the Influenza and more recently the Covid-19 (of the family of coronaviruses) exhibit lower fatality rates but can however cause major health issues especially when vaccines are now yet available [5]. Additional difficulties in virus fight are the possible mutations operated by viruses as well as the eventuality of animal-to-human transfers... There is thus a need to develop virus fight strategies.

\section{The Challenges of Virus Fight}

Especially when the human body cannot combat the viral infection by itself, if the symptoms are very invalidating, or else in the case of rapidly spreading viruses, a medical arsenal is needed to limit new infections in healthy people and help infected patients recover. Therapeutic tools rely on the search for antiviral compounds, in the development of vaccines, but also of non-vaccine immunotherapy strategies with the view to boost the immune response of the body [6,7]. However, as in most therapeutic approach, there is a need to develop galenic pharmaceutical formulations that may allow a successful administration to the patients and an optimized in vivo efficacy of the active agents at the 
desirable dose. Taking into account the administration route (oral, nasal, by injection...), there is a need to develop galenic forms for transporting the drug/active agents while providing a stabilizing or protective effect, controlling the release, and possibly playing an enhancing effect. Here, nanotechnologies come into play...

\section{The Role of Nanotechnologies in Virus Infection Handling}

The "nanoworld" is omnipresent in our modern societies. Whether in (opto)electronics and telecommunications, energy storage, sensors, transport, pollution control, biomedical sciences and other domains, nano-objects surround us. In link with the human body, it is not surprising that nanotechnologies should play a determining role in biomedicine, especially taking into account that most biologically relevant molecules are smaller than $10 \mathrm{~nm}$ and thus belong to this nanoworld [8]. Also, another significant feature of nano-objects is their capacity to exhibit enhanced or new properties in comparison to their macroscopic counterparts, due to their high surface-to-volume ratios. In this context, nanotechnologies can prove helpful for the handling of virus infections, via several aspects (Figure 1): nanosystems can find applications for virus detection and the setup of diagnostic tests, for the separation/isolation of viral particles, for playing the role of adjuvants in vaccine formulations, and also as nanocarriers of active agents in non-vaccine approaches. Finally, some nano-objects can exhibit by themselves a direct antiviral activity. Illustrations of virus fight strategies involving nanotechnologies are given in the following

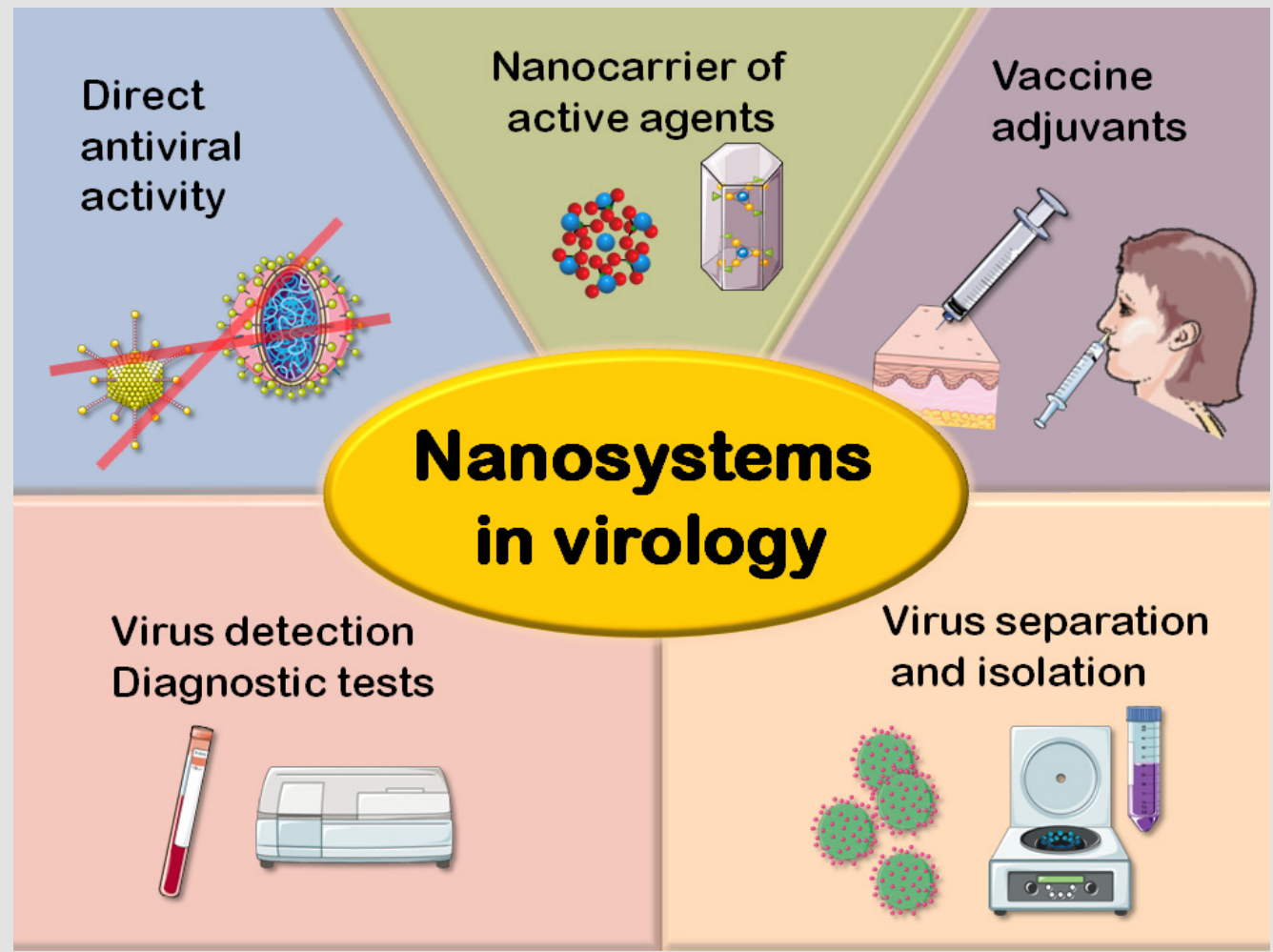

Figure 1: Main uses of nanotechnology in virus fight.

\section{Separation/Isolation of Viral Particles}

In the fight against the propagation of viruses, there is a need to be able to separate the viral particles from their evolving environment. This is in particular true to eliminate viruses from water, e.g. to limit drinking water contaminations. Several strategies have been investigated, including the use of nanocomposite membranes incorporating electrospun nanofibers, which was assessed relatively to the Semliki Forest virus in solution, pointing out a high virus removal efficiency (up to $98.9 \%$ ) [9]. The selective adsorption of coronaviruses was also reported using biopolymer nano/microspheres based on chitosan and genipin [10] and can be found useful for virus removal but also in virology research for isolating the viral particles.

\section{Detection and Diagnostics}

Another domain of interest for nanotechnologies in virology addresses the detection of viruses and the related setup of diagnostic tests. An example concerns the use of silver (Ag) NPs associated to DNA strands for the detection of the Dengue virus, via a colorimetric detection process, and high sensitivity was reported to detect different Dengue serotype RNAs [11]. Iron oxide nanoparticles of several compositions have also been used for virus detection purposes, among other nanosystems, as illustrated in the case of the Zika virus, exploiting a magnetic relaxation mechanism [12]. In another context, it may be mentioned that nanotechnologies may also be exploited to detect/titrate antiviral 
drugs, as it was reported for instance using a zinc oxide (ZnO) NPs - modified carbon electrode for the detection of Acyclovir via an electrochemical response [13].

\section{Intrinsically Antiviral Nanosystems}

Several nanosystems were found to exhibit by themselves an intrinsic antiviral activity [14]. This is for example the case of Ag NPs that were extensively studied [15] with regard to several viruses including HIV, Herpes simplex virus, Poliovirus type-1 and others. Various mechanisms were considered, in a virus-dependent manner, such as imposed conformational changes in the virus or membrane biochemical modifications (e.g. by interaction with sulfhydryl groups) upon contact with the NPs, or else a modification of the virus genome [14-17]. In many cases, the Ag NPs were coated with an organic corona (e.g. polysaccharides, polyvinylpyrrolidone (PVP), sialic acid...) and a large variety of conditions have been tested, aiming various modes of antiviral action [15]. An interest in using nanosized systems in virus fight is also the possibility to adjust their dimensions to the scale of viral particles, as was illustrated in the case of the Poliovirus (viral particles size range of 25-30 nm) [18]. These authors suggested that "small" Ag NPs, typically around $7 \mathrm{~nm}$, may easily interact with the larger viral particles, therefore preventing their binding to cell receptors. Besides silver, gold ( $\mathrm{Au}$ is another noble metal that was tentatively studied, and antiviral outcomes of Au NPs were reported for example versus HIV and Foot-and-mouth viruses. One proposed mechanism of action was related to the blocking of receptors involved in virus entry into host cells $[14,19]$.

Besides metal particles, several other systems were also investigated and used in virus fight. Carbon-based nanomaterials (based on fullerenes, carbon nanotubes, graphene-derived compounds...) have been considered, but to date their use in virology remains scarce [14]. Glyco-dendro-fullerenes have for example been studied in relation with the Ebola virus and showed promising results [20]. Here, the accessibility of fullerene ligands to viral receptors appears to be directly linked to their antiviral activity. The potential effects of selenium (Se), a non-metal element naturally present in vivo supporting the activity of immune cells, were also investigated: Se NPs were reported to be effective in conjunction with the antiviral drug zanamivir for a synergistic treatment of the H1N1 Influenza virus [21].

Nanosized oxide particles have also been quite widely explored in view of direct antiviral activity. Iron oxides were for instance found to be active against Hepatitis C [14,22]. In the treatment of the $\mathrm{H} 1 \mathrm{~N} 1$ Influenza virus, $\mathrm{Fe}_{3} \mathrm{O}_{4} \mathrm{NPs}$ proved efficient in vitro (at the dose of $6.5 \mathrm{pg}$ iron oxide $/ \mathrm{mL}$ ) in the inhibition of the virus when compared to the control [23]. Titanium dioxide $\left(\mathrm{TiO}_{2}\right)$ NPs were explored sporadically, e.g. in relation with the Influenza virus [24] although their potential toxicity is still being questioned nowadays [25]. Zirconia $\left(\mathrm{ZrO}_{2}\right)$ NPs (positively charged, $200 \mathrm{~nm}$ wide) were shown recently to inhibit viral replication in the mouse with regards to the H5N1 Influenza virus and to protect the mice against the H5N1 infection [26]. This effect was related to an enhancement of the innate immunity in the early stage of infection, a reduction of the viral load and the limitation of pro-inflammatory cytokines influx in the lungs. Zinc oxide (ZnO) NPs were also documented in the fight against the H1N1 Influenza virus [27]. In that study, surface coating of the NPs with polyethyleneglycol (PEG) macromolecules was found to increase very significantly the virus inhibition rate compared to uncoated NPs, from 52.2 to $94.6 \%$. This effect was related by the authors to the smaller particle size of the coated particles, which may penetrate passively in larger amount into cells.

Copper oxides were also found to exhibit some antiviral properties. For instance, cuprous oxide (theoretically $\mathrm{Cu}_{2} \mathrm{O}$ but no characterization was provided) NPs were reported to inhibit the effect of the Hepatitis $C$ virus in vitro, which was related to an inhibition of cell entry for virus pseudoparticles [28]. Cupric oxide (CuO) NPs (40 nm in size) were, on the other hand, shown recently to be active against the Herpes simplex virus type 1, HSV-1, with a reduction of $83.3 \%$ of viral load in Vero cells [29]. Although the exact mechanisms of action are not yet elucidated, the authors hypothesized an interference of the NPs with viral replication stages. The potentiality of released copper ions to result in the production of oxygenated radicals generating DNA denaturation and phospholipid membrane damages was also envisaged, as already pointed out in the fight against bacteria [29,30]. Tin oxide $\left(\mathrm{SnO}_{2}\right)$ nanowires were also tested against the HSV-1 virus and shown to suppress virus entry and interfere with membrane fusion processes [31]. Mesoporous silica $\left(\mathrm{SiO}_{2}\right)$ NPs have been investigated for their potential antiviral properties, as in the fight against HIV [32]. Here, the hydrophilic/hydrophobic modularity of the particles, essentially via surface functionalization, is thought to play a direct role in preventing regular virus transduction by establishing strong interactions with the virus envelope. Apart from inorganic NPs, a wealth of polymeric nanosystems including dendrimers, liposomes, chitosan-based NPs, etc. have also been considered, although in a limited manner for antiviral applications [14]. However, it was essentially for their drug-carrier capacities rather than an intrinsic antiviral potential.

\section{Nanocarriers of Active Agents}

In the field of drug transport and release, nanotechnology is also often at the center of antiviral strategies. For example, the conjugation of noble metal NPs (Ag and $\mathrm{Au}$ ) with the antiviral peptide FluPep was reported to enhance the inhibition of the Influenza virus compared to the peptide alone, which may be related to the high grafting density of the FluPep ligand on the surface of the NPs [33]. Cerium oxide $\left(\mathrm{CeO}_{2}\right)$ NPs were reported in link with Vesicular stomatitis virus [34] and in association with interferon to allow its prolonged effect in the treatment of Herpes [35]. Other particulate systems were also investigated. 
For instance, lipid-coated mesoporous $\mathrm{SiO}_{2}$ NPs were used to carry and deliver the ML336 antiviral agent to inhibit encephalitic Alphavirus infection [36]. The lipid-coated aimed at improving the colloidal stability of the particles, and the NPs efficacy was shown in vitro and in vivo, leading to a significant decrease in viral load. As mentioned previously, polymer-based NPs may be used to deliver active antiviral agents. For example, Rhodamine B-labeled poly(glycerol-adipate) NPs were prepared and contacted in vitro with a hepatic cell line transfected with Hepatitis $C$ virus RNA, evidencing a greater NPs uptake in the cells compared to the non-transfected cells [37]. This observation directly illustrates one possible advantage of nanoparticle-based drug delivery as compared to the administration of the free drug, allowing for a potentially higher intracellular drug release (provided that the NPs may be sufficiently loaded with the drug); and this strategy may be expanded to other types of NPs thus opening new perspectives of research. Also, the association of drugs to nanocarriers may offer the possibility to target more precisely the affected organs and avoid accumulation of the drug at "off-target" sites [37].

\section{Vaccine Adjuvants}

The development of vaccines is one of the keys to virus fight. In continuation with the idea of transporting active agents as in the above section, adjuvants are often included in the formulation of vaccines. Adjuvants may indeed play several potential roles: to optimize or prolong the delivery of the active components, to boost the antiviral activity, to limit the antigen dose, etc. The adjuvancy strategy was discovered in the 1920s-1930s by Glenny et al. [38] who stated that "if the [antigen] is too rapidly absorbed or eliminated, only slight stimulation may occur, however large the dose injected". This work was relating in particular to the use of potassium alum as additive to "precipitate the toxoid" for treating Diphtheria. Although this pathology is linked to a bacterium rather than a virus, the concept of adjuvants was born. Nanosized adjuvants are particularly well suited for this task, taking into account the submicron scale in question here. Several strategies may be found. Nano-emulsion is one of them, as illustrated for example in the treatment of the Foot-and-mouth disease virus, where a water-in-oil nano-emulsion adjuvant was prepared and tested, leading to a higher cell-mediated immune response than the commercially available ISA-206 adjuvant[39].

Organic, polymer-based nanoparticles were also found pertinent in the role of adjuvant, as illustrated by chitosan-based NPs loaded with inactivated Poliovirus and coated with alginate, where electrostatic interactions explained the retention of charged antigenic particles [40]. In another context, poly- $\gamma$-glutamic acid NPs were also tested in the mouse versus the Influenza virus, in the form of a mucosal adjuvant, and proved to induce cell-mediated immune responses and a neutralization of antibody production [41]
Inorganic NPs were often considered as vaccine adjuvants (as pioneered by Glenny et al. with alum [38]), taking into account their stability, large surface area and tailorable physical-chemical characteristics. Whether already approved by healthcare Regulatory agencies or still in development, inorganic adjuvants have been reviewed on several occasions taking into account their significance in this field (e.g. [42-44]). Additionally, the role of several physicalchemical features such as chemical composition, nanoparticle size, morphology, shape, surface charge and hydrophobicity has been reviewed lately [44]. Universal conclusions cannot be made straightforwardly as biological outcomes are rather dependent on the type of nanosystem considered. Aluminum-based adjuvants, represented by the generic term "alum", have been widely used in vaccines since the 1930s. However, some potential drawbacks may be identified; in particular aluminum was reported to be neurotoxic and potentially related to Alzheimer's disease [45] and other pathologies, although some aspects are still being debated on this matter. Also, the activity of alum relies essentially on humoral immune response (Th2 helper $\mathrm{T}$ lymphocytes) and is "relatively ineffective for vaccines requiring a Th1 response" as for example for treating the HIV virus [44]. Finally, new adjuvants may prove to be ultimately more efficient than alum, since nanotechnologies become increasingly more elaborate.

The search for alternative compounds to alum opened the way to several exploratory works. ZnO NPs were tested in mice and showed a boosting effect on the immune system (on lymphocytes Th2 but not Th1, as for alum) [46]. It may be noted that a more balanced Th1 to Th2 ratio was obtained with cobalt oxide $\left(\mathrm{Co}_{3} \mathrm{O}_{4}\right)$ NPs [47]. Noble metal NPs ( $\mathrm{Ag}, \mathrm{Au})$ can also be suited as vaccine adjuvants. An example is the use of Au NPs in the development of DNA vaccines for the HIV virus [48]. The role of the shape (spherical, rod, cubic) and size of Au NPs coated with West Nile virus (WNV) envelope protein has been scrutinized in vitro and in vivo [49]. Different cytokine pathways were activated depending on these characteristics. Other alternatives to alum have been explored, including in a comparative study in rats carried out in the 1990s and involving iron oxides, alumina $\left(\mathrm{Al}_{2} \mathrm{O}_{3}\right), \mathrm{SnO}_{2}, \mathrm{ZrO}_{2}, \mathrm{SiO}_{2}$, ground glass and talcum [50]. The authors reported a correlation between "the magnitude of adjuvancy" and the degree of inflammatory response and surface area while the hydrophilic/hydrophobic character of the particles did not seem directly correlated.

In that work, alumina and iron oxides appeared as the most promising among the compounds tested. In a recent study, dendrimer-like mesoporous $\mathrm{SiO}_{2}$ NPs were developed to address the Foot-and-mouth disease virus and were found to be well adapted as nanocarriers of large proteins/antigens [51]. Layered double hydroxides (LDHs) were tested as potential vaccine adjuvants since years 2010s [42,52,53]. A study was, in particular, undergone with various types of LDHs and the in vitro response 
of the immune system was found to be greatly dependent on the LDH chemical composition $[43,52]$. These systems may represent a relevant family of vaccine adjuvants to further develop in the future.

Besides alum, calcium phosphates (CaP) represent another major family of inorganic compounds that have been explored for years in the domain of vaccine adjuvants. This may be rationalized on the basis of their similarity to the mineral part of bones and teeth (apatitic CaP have been present naturally in all
Vertebrates for millions of years) and may thus be considered as "intrinsically" biocompatible [54]. Furthermore, CaP compounds - and more particularly nanocrystalline apatites - exhibit a high surface reactivity and are greatly tailorable in terms of chemical composition and surface features, opening the way to a wealth of biomedical applications as reviewed recently [55] (Figure 2). Plus, they are biodegradable in vivo and lead to natural metabolites (calcium and phosphate ions already present in body fluids) that the host body can eliminate easily.

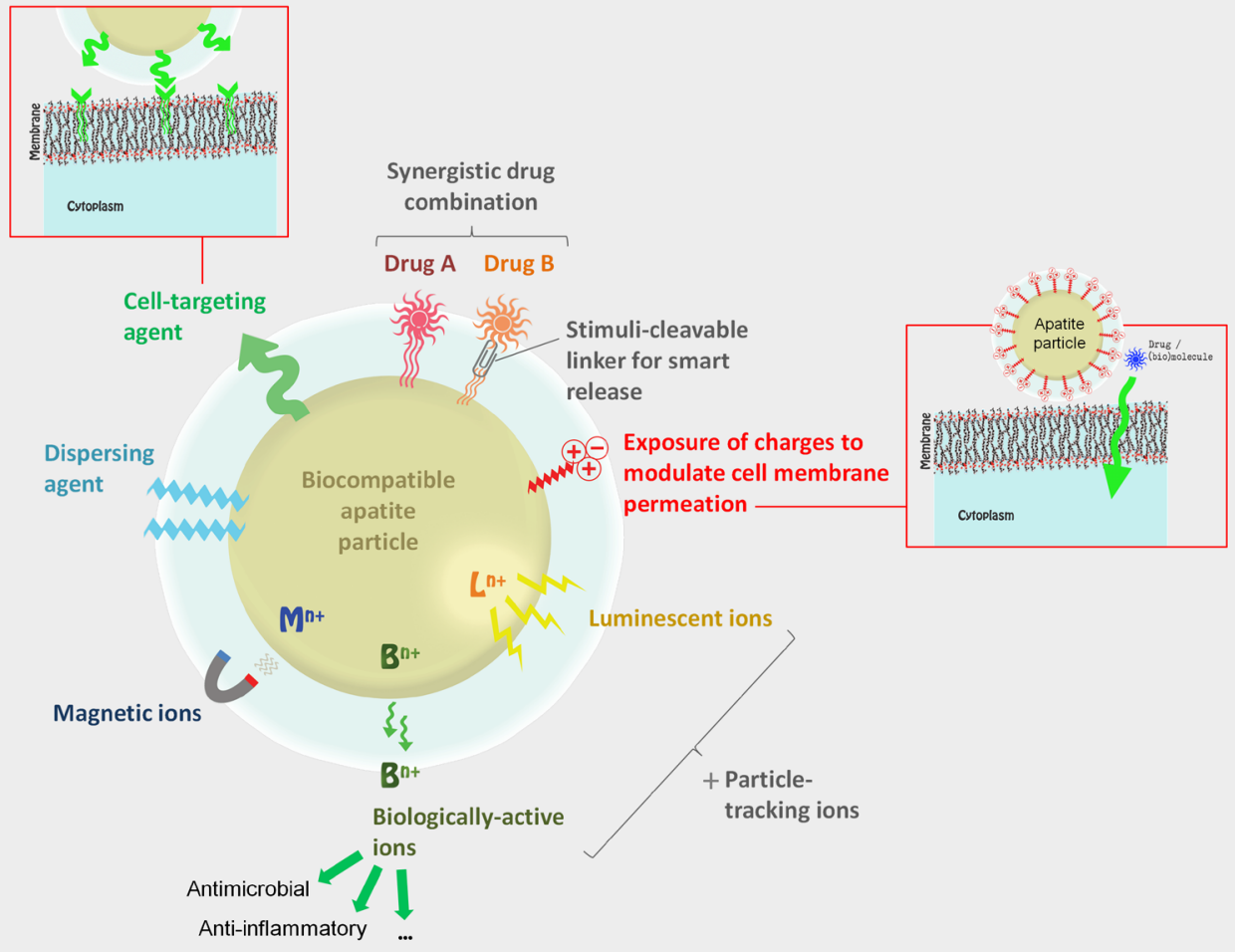

Figure 2: Nanocrystalline calcium phosphate apatites: a platform for nanomedicine (modified from ref. 55).

\section{Calcium Phosphates: Relevant Bioinspired Compounds}

The first use of $\mathrm{CaP}$ as vaccine adjuvant was reported for the delivery of Diphtheria anatoxin by Relyveld et al. in the 1960s [56] as an alternative to pre-existing aluminum-based formulations, for treating allergic patients. In this case, brushite $\left(\mathrm{CaHPO}_{4}\right)$ particles were used. The authors reported several advantages of $\mathrm{CaP}$ adjuvants: no signs of allergy were detected, large scale production is easy, antigen adsorption is complete and immediate at neutral $\mathrm{pH}$, and it does not have the inconvenient of aluminum phosphate which requires a maturation stage at acidic $\mathrm{pH}$ for adsorption to be complete. Also, the formulations obtained were stable over several years [56]. CaP have then been used in vaccinal fight against several viral infections as Poliovirus and Hepatitis B [42] . However, often, no precise characterization information was given about the used CaP particles. Jiang et al. have reported a physicalchemical analysis of a commercial CaP adjuvant and showed that it was composed of a nonstoichiometric hydroxyapatite phase,
$\mathrm{Ca}_{10-\mathrm{x}}\left(\mathrm{PO}_{4}\right)_{6-\mathrm{x}}\left(\mathrm{HPO}_{4}\right)_{\mathrm{x}}(\mathrm{OH})_{2-\mathrm{x}}$ [57]. Synthesis parameters of the CaP particles proved to condition the final association with the active component of the vaccine [58], and the degree of nonstoichiometry appeared to be one relevant criterion. Indeed, temperature, $\mathrm{pH}$ and maturation time are key parameters that may control the final characteristics of nanocrystalline apatites [59].

Recently, CaP adjuvants have been prepared with more controlled features than traditional ones [60], although detailed structural and compositional analyses were not reported. The absence of side effects and the potency of the CaP adjuvant were shown for example in a study on Herpes simplex virus 2 (HSV-2) [60], where the authors reported that "[these data] strongly suggest that CaP nanoparticles significantly enhance the antibody response to HSV-2 antigen". Here, the release of the antigen from the CaP surface was considered to happen progressively over an extended period of time. In another study, other authors claimed the effect of CaP nanoparticles for the setup of a vaccinal formulation (final 
NPs concentration: $0.3 \%$ wt./vol., typical NPs size: $450-500 \mathrm{~nm}$ ) in relation to the H1N1 Influenza virus in infected mice [61]. Despite the absence of structural and compositional information on the particles used, the formulation showed promise in its efficiency and for antigen dose-sparing. A Phase I human clinical study is in progress in the US where CaP NPs were injected intramuscularly [62].

Related US patent literature indicates that "there is [a] need for calcium phosphate core particles that can be effectively used as supports and matrices for sustained release of polynucleotide material (DNA or RNA) encoding immunogenic polypeptides" [63]. Studies in other scientific domains have indeed pointed out the possible adsorption of (poly)nucleotides onto apatite nanocrystals [64-66]. Also, transfection was reported to be feasible using apatite NPs as carriers of nucleic acids [67]. The use of CaP NPs (50-100 $\mathrm{nm}$ ) to develop a DNA vaccine against the Foot-and-mouth disease virus was also reported, and showed similar in vitro transfection efficacy as commercial lipofectamine as well as significant induced humoral immune response in vivo on rodents [68]. Another desirable feature for vaccine adjuvants is the possibility to envisage a variety of administration routes. Beyond injections, nasal/ mucosal administration is for example also appealing and may be considered by patients as less invasive. The possible administration of CaP NPs (size $<50 \mathrm{~nm}$ ) by inhalation was reported, although in another context (cardiovascular disorders) [69], and access to the pulmonary system of rodents was shown to be successful. In the field of vaccines, mucosal immunity was reported using CaP NPs as adjuvant in mice relatively to the Herpes Simplex Virus Type 2 [70]. One other appealing feature of CaP compounds, and especially of apatites, is their capacity to accommodate a large number of ionic substituents, therefore allowing for a modulation of physicalchemical but also biological properties [55].

In view of cancer immunotherapy, $\mathrm{Mg}$ - and $\mathrm{Zn}$-doped $\mathrm{CaP}$ particles ( $\boldsymbol{\beta}$-tricalcium phosphate ( $\boldsymbol{\beta}$-TCP) then apatite) were considered [71], and some compositions exhibited enhanced antitumor activity. Still in cancer immunotherapy, a pilot study on the development of a therapeutic antitumor vaccine employing CaP particles and self-antigens was reported [72], e.g. to face breast carcinoma or melanoma. The formulation (although made of microparticles) was well tolerated by patients and led to clinical improvements in some patients (activation of T-cell response) Although this does not address viral infections, these examples give information of how CaP-bearing vaccine formulations behave in humans. The potential role of CaP particles shape and composition on adjuvant efficacy was also mentioned, but without a systematic study $[44,73]$. In addition, the association of CaP NPs with active molecules can be made either during $\mathrm{CaP}$ precipitation or in a subsequent step via adsorption on pre-existing particles. The adsorption capabilities of nanocrystalline biomimetic apatites are indeed well-known, as was demonstrated for a wealth of drugs/ biomolecules in several contexts (e.g. antibacterial enzymes [74], anti-tumor and anti-resorptive drugs [75-77], antibodies [78], antibiotics [79], etc.). With all these appealing features, bio-inspired calcium phosphates appear very promising as tailorable vaccine adjuvants to face several scenarios in virus fight and beyond.

\section{Concluding Remarks}

Nanotechnology is part of our societies and plays a key role in the fight against infections, including for addressing a large variety of viruses. Whether as drug nanocarriers, vaccine adjuvants or for intrinsic antiviral properties, the inclusion of nanosystems in therapeutic galenic formulations has permitted significant improvements in terms of active agent stabilization, antigen dose sparing, controlled/prolonged release, adequate exposure of antigens, improved cell uptake, etc. Besides, nanosystems proved helpful for the separation and isolation of viral particles as well as in the development of detection and diagnostics tools.

Among appealing nanosystems, inorganic nanoparticles have in particular raised interest thanks to wide possibilities offered in terms of size, shape, porosity, resorption rate, surface features, etc. Noble metals, metal oxides, mesoporous silica and calcium phosphates have been especially investigated, besides aluminumbased compounds whose potential neural toxicity has been debated. The incorporation of nanosystems in therapeutic formulations requires approval from Regulatory agencies, but also more and more public acceptance; therefore privileging highly biocompatible compounds whenever possible is a safe prerequisite. Bio-inspired calcium phosphates, proved to be increasingly appealing for use in nanomedicine as in virus fight, and should allow even more original uses in the future. However, care should be taken in the characterization of the particles produced, and the use of complementary techniques is recommended to assess structural and compositional features among the CaP family of compounds. Independently of the type of nanosystem considered, exploration of the mechanism(s) underlying the enhancement of antiviral activity is necessary in order to better understand the key parameters.

\section{Author's Bibliography Links}

ORCID: https://orcid.org/0000-0002-8471-8719

GOOGLE SCHOLAR: https://scholar.google.com/citations?user=tZ9GEBkAAAAJ\&hl=en

\section{Competing Interests}

The author declares that there are no competing interests.

\section{Acknowledgement}

“The author thanks the GdR CNRS 2088 BIOMIM (Biomimétisme et Bioinspiration), France, for relevant discussions. 


\section{References}

1. Yadvinder S, Bijay S, Timsina J (2005) Crop Residue Management for Nutrient Cycling and Improving Soil Productivity in Rice-Based Cropping Systems in the Tropics. In Advances in Agronomy, Academic Press 85: 269-407.

2. Sender R, Fuchs S, Milo R (2016) Revised Estimates for the Number of Human and Bacteria Cells in the Body. PLoS biology 14(8): e1002533-e1002533.

3. Mc Fall-Ngai M (2007) Care for the community. Nature 445 (7124) : 153 153.

4. Prasad BVV, Schmid MF (2012) Principles of virus structural organization. Advances in experimental medicine and biology 726: 17-47.

5. https://www.livescience.com/56598-deadliest-viruses-on-earth.html; https://www.statista.com/statistics/1095129/worldwide-fatalityrate-of-major-virus-outbreaks-in-the-last-50-years/

6. Dalgleish AG (2014) Vaccines versus immunotherapy: overview of approaches in deciding between options. Human vaccines \& immunotherapeutics 10(11): 3369-3374.

7. Dibo M, Battocchio EC, Dos Santos Souza LM, Da Silva MDV, Banin-Hirata BK, et al. (2019) Antibody Therapy for the Control of Viral Diseases: An Update. Curr Pharm Biotechnol 20(13): 1108-1121.

8. Milioni D, Tsortos A, Velez M, Gizeli E (2017) Extracting the Shape and Size of Biomolecules Attached to a Surface as Suspended Discrete Nanoparticles. Analytical Chemistry 89(7): 4198-4203.

9. Al-Attabi R, Rodriguez-Andres J, Schütz JA, Bechelany M, Des Ligneris E, et al. (2019) Catalytic electrospun nano-composite membranes for virus capture and remediation. Separation and Purification Technology 229: 115806.

10. Ciejka J, Wolski K, Nowakowska M, Pyrc K, Szczubiałka K (2017) Biopolymeric nano/microspheres for selective and reversible adsorption of coronaviruses. Materials Science and Engineering 76: 735-742.

11. Vinayagam S, Rajaiah P, Mukherjee A, Natarajan C (2018) DNAtriangular silver nanoparticles nanoprobe for the detection of dengue virus distinguishing serotype. Spectrochim Acta A Mol Biomol Spectrosc 202: 346-351.

12. Shelby T, Banerjee T, Zegar I, Santra S (2017) Highly Sensitive, Engineered Magnetic Nanosensors to Investigate the Ambiguous Activity of Zika Virus and Binding Receptors. Scientific Reports 7(1): 7377.

13. Pavamana M, Shetti NP, Malode SJ, Bukkitgar SD (2019) Nano level detection and analysis of an antiviral drug at $\mathrm{ZnO}$ nanoparticles modified sensor. Materials Today: Proceedings 18: 1568-1573.

14. Kerry RG, Malik S, Redda YT, Sahoo S, Patra JK, et al. (2019) Nanobased approach to combat emerging viral (NIPAH virus) infection. Nanomedicine 18: 196-220.

15. Galdiero S, Falanga A, Vitiello M, Cantisani M, Marra V, et al. (2011) Silver nanoparticles as potential antiviral agents. Molecules 16(10): 8894918.

16. Lara HH, Ayala-Nuñez NV, Ixtepan-Turrent L, Rodriguez Padilla C (2010) Mode of antiviral action of silver nanoparticles against HIV-1. Journal of Nanobiotechnology 8(1): 1.

17. Rónavári A, Kovács D, Igaz N, Vágvölgyi C, Boros IM, et al. (2017) Biological activity of green-synthesized silver nanoparticles depends on the applied natural extracts: a comprehensive study. International journal of nanomedicine 12: 871-883.

18. Huy TQ, Hien Thanh NT, Thuy NT, Chung PV, Hung PN, et al. (2017) Cytotoxicity and antiviral activity of electrochemical - synthesized silver nanoparticles against poliovirus. J Virol Methods 241: 52-57.

19. Vijayakumar S, Ganesan S (2012) Gold nanoparticles as an HIV entry inhibitor. Curr HIV Res 10 (8) : 643-646.
20. Luczkowiak J, Muñoz A, Sánchez-Navarro M, Ribeiro-Viana R, Ginieis A et al. (2013) Glycofullerenes Inhibit Viral Infection. Biomacromolecules 14(2): 431-437.

21. Lin Z, Li Y, Guo M, Xiao M, Wang C, et al. (2017) Inhibition of H1N1 influenza virus by selenium nanoparticles loaded with zanamivir through p38 and JNK signaling pathways. RSC Advances 7(56): 3529035296.

22. Delaviz N, Gill P, Ajami A, Aarabi M (2015) Aptamer-conjugated magnetic nanoparticles for the efficient removal of HCV particles from human plasma samples. RSC Advances 5(97): 79433-79439.

23. Kumar R, Sahoo GC, Chawla-Sarkar M, Nayak MK, Trivedi K, et al. (2016) Antiviral effect of Glycine coated Iron oxide nanoparticles iron against H1N1 influenza A virus. International Journal of Infectious Diseases 45: 281-282.

24. Mazurkova NA, Spitsyna YE, Shikina NV, Ismagilov ZR, Zagrebelnyi SN (2010)Interaction of titanium dioxide nanoparticles with influenza virus. Nanotechnologies in Russia 5(5): 417-420.

25.Winkler HC, Notter T, Meyer U, Naegeli H (2018) Critical review of the safety assessment of titanium dioxide additives in food. J Nanobiotechnology 16 (1) : 51 .

26. Huo C, Xiao J, Xiao K, Zou S, Wang M, et al. (2020) Pre-Treatment with Zirconia Nanoparticles Reduces Inflammation Induced by the Pathogenic H5N1 Influenza Virus. International journal of nanomedicine 15: 661674.

27. Ghaffari H, Tavakoli A, Moradi A, Tabarraei A, Bokharaei-Salim F,et al.(2019) Inhibition of H1N1 influenza virus infection by zinc oxide nanoparticles: another emerging application of nanomedicine. Journal of Biomedical Science 26(1): 70.

28. Hang X, Peng H, Song H, Qi Z, Miao X, et al. (2015) Antiviral activity of cuprous oxide nanoparticles against Hepatitis C Virus in vitro. J Virol Methods 222: 150-157.

29. Tavakoli A, Hashemzadeh MS (2020) Inhibition of herpes simplex virus type 1 by copper oxide nanoparticles. J Virol Methods 275: 113688.

30. Warnes SL, Summersgill EN, Keevil CW (2015) Inactivation of murine norovirus on a range of copper alloy surfaces is accompanied by loss of capsid integrity. Appl Environ Microbiol 81(3): 1085-1091.

31. Trigilio J, Antoine TE, Paulowicz I, Mishra YK, Adelung R, et al. (2012) Tin Oxide Nanowires Suppress Herpes Simplex Virus-1 Entry and Cellto-Cell Membrane Fusion. PLoS ONE 7(10): e48147.

32. De Souza ESJM, Hanchuk TD, Santos MI, Kobarg J, Bajgelman MC, et al. (2016) Viral Inhibition Mechanism Mediated by Surface-Modified Silica Nanoparticles. ACS Appl Mater Interfaces 8(26): 16564-16572.

33. Alghrair ZK, Fernig DG, Ebrahimi B (2019) Enhanced inhibition of influenza virus infection by peptide-noble metal nanoparticle conjugates. Beilstein J Nanotechnol 10 : 1038-1047.

34. Zholobak NM, Olevinskaia ZM, Spivak N, Shcherbakov AB, Ivanov VK, et al. (2010) Antiviral effect of cerium dioxide nanoparticles stabilized by low-molecular polyacrylic acid. Mikrobiol Z 72 (3): 42-47.

35. Shydlovska O, Kharchenko E, Osenniy I, Spivak M, Shcherbakov A, et al. (2018) Nanoparticles of cerium dioxide - an effective antiviral agent and adjuvant of biologically active molecules. ScienceRise:Biological Science 1(10): 26-30.

36. La Bauve AE, Rinker TE, Noureddine A, Serda RE, Howe JY, et al. (2018) Lipid-Coated Mesoporous Silica Nanoparticles for the Delivery of the ML336 Antiviral to Inhibit Encephalitic Alphavirus Infection. Scientific Reports 8(1): 13990.

37. Abo-zeid Y, Urbanowicz RA, Thomson BJ, Irving WL, Tarr AW, et al. (2018) Enhanced nanoparticle uptake into virus infected cells: Could nanoparticles be useful in antiviral therapy ? International Journal of Pharmaceutics 547 (1): 572-581. 
38. Glenny AT, Buttle GAH, Stevens MF (1931) Rate of disappearance of diphtheria toxoid injected into rabbits and guinea - pigs: Toxoid precipitated with alum. The Journal of Pathology and Bacteriology 34(2): 267-275.

39. Chen Z, Zhang S, Li Z, Ma G, Su Z (2017) Construction of a stable w/o nano-emulsion as a potential adjuvant for foot and mouth disease virus vaccine. Artificial cells, nanomedicine, and biotechnology 45(5): 897906.

40. Tafaghodi M, Kersten G, Jiskoot WIM (2014) Nano-adjuvanted polio vaccine : Preparation and characterization of chitosan and trimethylchitosan ( TMC ) nanoparticles loaded with inactivated polio virus and coated with sodium alginate. Nanomedicine Journal 1(4): 220228.

41. Okamoto S, Matsuura M, Akagi T, Akashi M, Tanimoto T, et al. (2009) Poly(gamma-glutamic acid) nano-particles combined with mucosal influenza virus hemagglutinin vaccine protects against influenza virus infection in mice. Vaccine 27(42): 5896-5905.

42. Paneque-Quevedo AA (2013) Inorganic compounds as vaccine adjuvants. Biotecnología Aplicada 30: 250-256.

43. Maughan CN, Preston SG, Williams GR (2015) Particulate inorganic adjuvants: recent developments and future outlook. J Pharm Pharmacol 67(3): 426-449.

44. Li X, Wang X, Ito A (2018) Tailoring inorganic nanoadjuvants towards next-generation vaccines. Chemical Society Reviews 47(13): 49544980.

45. Tomljenovic L (2011) Aluminum and Alzheimer's disease: after a century of controversy, is there a plausible link? J Alzheimers Dis 23(4): 567-598.

46. Matsumura M, Nagata M, Nakamura K, Kawai M, Baba T, et al. (2010) Adjuvant effect of zinc oxide on Th2 but not Th1 immune responses in mice. Immunopharmacol Immunotoxicol 32(1): 56-62.

47. Cho WS, Dart K, Nowakowska DJ, Zheng X, Donaldson K, et al. (2012) Adjuvanticity and toxicity of cobalt oxide nanoparticles as an alternative vaccine adjuvant. Nanomedicine (Lond) 7(10): 1495-1505.

48. Xu L, Liu Y, Chen Z, Li W, Wang L, et al. (2012) Surface-engineered gold nanorods: promising DNA vaccine adjuvant for HIV-1 treatment. Nano Lett 12(4): 2003-2012

49. Niikura K, Matsunaga T, Suzuki T, Kobayashi S, Yamaguchi H, et al. (2013) Gold Nanoparticles as a Vaccine Platform: Influence of Size and Shape on Immunological Responses in Vitro and in Vivo. ACS Nano 7(5): 39263938.

50. Naim JO, Van Oss CJ, Wu W, Giese RF, Nickerson PA (1997) Mechanisms of adjuvancy: I Metal oxides as adjuvants. Vaccine 15(11): 1183-1193.

51. Liu Z, Ru J, Sun S, Teng Z, Dong H, et al. (2019) Uniform dendrimer-like mesoporous silica nanoparticles as a nano-adjuvant for foot-and-mouth disease virus-like particle vaccine. Journal of Materials Chemistry B $7(21): 3446-3454$.

52. Williams GR, Fierens K, Preston SG, Lunn D, Rysnik O, et al. (2014) Immunity induced by a broad class of inorganic crystalline materials is directly controlled by their chemistry. Journal of Experimental Medicine 211(6): 1019-1025.

53. Li A, Qin L, Zhu D, Zhu R, Sun J, et al. (2010) Signalling pathways involved in the activation of dendritic cells by layered double hydroxide nanoparticles. Biomaterials 31(4): 748-756.

54. Gomez-Morales J, Iafisco M, Delgado-Lopez JM, Sarda S, Drouet C (2013) Progress on the preparation of nanocrystalline apatites and surface characterization: Overview of fundamental and applied aspects. Progress in Crystal Growth and Characterization of Materials 59(1): $1-46$.
55. Drouet C, Choimet M, Simon M, Devès G, Barberet P, et al. (2020) Colloidal Apatite Particles : A Multifunctional Platform in (Nano)Medicine. Juniper Online Journal of Materials Science 6(1): 555676.

56. Relyveld EH, Henocq E, Raynaud M (1964) Study of the antidiphtheria vaccination of allergic subjects with a pure anatoxin absorbed on calcium phosphate. Bulletin of the World Health Organization 30(3): 321-325.

57. Jiang D, Premachandra GS, Johnston C, Hem SL (2004) Structure and adsorption properties of commercial calcium phosphate adjuvant. Vaccine 23(5): 693-698.

58. Relyveld EH (1986) Preparation and use of calcium phosphate adsorbed vaccines. Dev Biol Stand 65: 131-136.

59. Vandecandelaere N, Rey C, Drouet C (2012) Biomimetic apatite-based biomaterials : on the critical impact of synthesis and post-synthesis parameters. J Mater Sci: Mater Med 23: 2593-2606.

60. He Q, Mitchell AR, Johnson SL, Wagner-Bartak C, Morcol T, et al. (2000) Calcium phosphate nanoparticle adjuvant. Clinical and diagnostic laboratory immunology 7(6): 899-903.

61. Morçöl T, Hurst BL, Tarbet EB (2017) Calcium phosphate nanoparticle (CaPNP) for dose-sparing of inactivated whole virus pandemic influenza A (H1N1) 2009 vaccine in mice. Vaccine 35 (35 Pt B): 4569-4577.

62. Morcol T, Nagappan P, Nerenbaum L, Mitchell A, Bell S (2008) Particulate Drug Delivery Systems for Protein Drugs: An overview of Noninvasive Insulin Delivery Using Calcium Phosphate Particle Technology pp. 223241.

63. Bell SJD, Morcol T, He Q , Therapeutic calcium phosphate particles and methods of manufacture and use. US Patent US8431221B2.

64. Grunenwald A, Keyser C, Sautereau AM, Crubézy E, Ludes B, et al. (2014) Adsorption of DNA on biomimetic apatites: Toward the understanding of the role of bone and tooth mineral on the preservation of ancient DNA. Applied Surface Science 292: 867-875.

65. Choimet M, Tourrette A, Drouet C (2015) Adsorption of nucleotides on biomimetic apatite: The case of cytidine $5^{\prime}$ monophosphate (CMP). Journal of Colloid and Interface Science 456: 132-137.

66. Hammami K, Feki HE, Marsan O, Drouet C (2015) Adsorption of nucleotides on biomimetic apatite: The case of adenosine $5^{\prime}$ monophosphate (AMP). Applied Surface Science 353: 165-172.

67. Welzel T, Radtke I, Meyer Zaika W, Heumann R, Epple M (2004) Transfection of cells with custom-made calcium phosphate nanoparticles coated with DNA. Journal of Materials Chemistry 14(14): 2213-2217.

68. Joyappa DH, Ashok Kumar C, Banumathi N, Reddy GR, Suryanarayana VVS (2009) Calcium phosphate nanoparticle prepared with foot and mouth disease virus P1-3CD gene construct protects mice and guinea pigs against the challenge virus. Veterinary Microbiology 139(1): 58-66.

69. Miragoli M, Ceriotti P, Iafisco M, Vacchiano M, Salvarani N, et al. (2018) Inhalation of peptide-loaded nanoparticles improves heart failure. Sci Transl Med 10(424).

70. He Q, Mitchell A, Morcol T, Bell SJD (2002) Calcium phosphate nanoparticles induce mucosal immunity and protection against herpes simplex virus type 2 . Clinical and diagnostic laboratory immunology 9(5): 1021-1024.

71. Wang X, Li X, Onuma K, Sogo Y, Ohno T, et al. (2013) Zn-and Mg-containing tricalcium phosphates-based adjuvants for cancer immunotherapy. Sci Rep pp. 2203.

72. Ciocca DR, Frayssinet P, Cuello-Carrión FD (2007) A pilot study with a therapeutic vaccine based on hydroxyapatite ceramic particles and selfantigens in cancer patients. Cell stress \& chaperones 12(1): 33-43.

73. Lee DD, Aiolova M, Calcium phosphate delivery vehicle and adjuvant. US Patent Application: 20030082232. 
74. Weber CG, Mueller M, Vandecandelaere N, Trick I, Burger-Kentischer A, et al. (2014) Enzyme-functionalized biomimetic apatites: concept and perspectives in view of innovative medical approaches. Journal of Materials Science-Materials in Medicine 25: 595-606.

75. Al-Kattan A, Errassifi F, Sautereau AM, Sarda S, Dufour P, et al. (2010) Medical potentialities of biomimetic apatites through adsorption ionic substitution, and mineral/organic associations: Three illustrative examples. Advanced Engineering Materials 12(7): B224-B233.

76. Sarda S, Iafisco M, Pascaud-Mathieu P, Adamiano A, Montesi M, et al. (2018) Interaction of Folic Acid with Nanocrystalline Apatites and Extension to Methotrexate (Antifolate) in View of Anticancer Applications. Langmuir 34(40): 12036-12048.

\section{ISSN: 2574-1241}

DOI: $10.26717 /$ BJSTR.2020.27.004500

Christophe Drouet. Biomed J Sci \& Tech Res

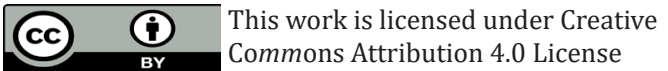

Submission Link: https://biomedres.us/submit-manuscript.php
77. Iafisco M, Drouet C, Adamiano A, Pascaud P, Montesi M, et al. (2016) Superparamagnetic iron-doped nanocrystalline apatite as a delivery system for doxorubicin. Journal of Materials Chemistry B 4(1): 57-70.

78. Iafisco M, Varoni E, Di Foggia M, Pietronave S, Fini $M$, et al. (2012) Conjugation of hydroxyapatite nanocrystals with human immunoglobulin $\mathrm{G}$ for nanomedical applications. Colloids and Surfaces B: Biointerfaces 90(1): 1-7.

79. Cazalbou S, Bertrand G, Drouet C (2015) Tetracycline-loaded biomimetic apatite: an adsorption study. J Phys Chem B 119(7): 3014-3024.

$\begin{array}{ll}\text { BIOMEDICAL } & \text { Assets of Publishing with us } \\ \text { RESEARCHES } & \text { - Global archiving of articles } \\ \text { - Immediate, unrestricted online access } & \text { - Rigorous Peer Review Process } \\ & \text { - Authors Retain Copyrights } \\ \end{array}$

